Sebastián Edwards, Toxic Aid. Economic Collapse and Recovery in Tanzania (Oxford: Oxford University Press, 2014).

\title{
LECTURA OBLIGADA PARA LOS INTERESADOS EN EL DESARROLLO ECONÓMICO
}

\section{Daniel Artana}

Fundación de Investigaciones Económicas Latinoamericanas (FIEL)

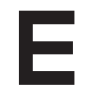

n este libro, Sebastián Edwards hace un análisis exhaustivo de la economía de Tanzania desde 1961 a 2011. El caso de Tanzania es particularmente interesante, porque el análisis se hace dividiendo la historia económica de este país en dos periodos: uno de gran fracaso económico, seguido por otro de (aparentemente) gran éxito, ambos con una activa participación de la comunidad internacional de donantes. Tanzania fue, de hecho, el principal receptor per cápita de ayuda internacional, muy por encima de otros países comparables de África.

El libro utiliza, en palabras del autor, la narrativa analítica. Así, se combinan a lo largo del texto detalles de momentos clave en la historia de Tanzania, en que se describe cuidadosamente la escena, con la rigurosidad del enfoque económico. Edwards aprovecha al máximo tres elementos que lo convierten en un candidato único para poder entender el caso bajo análisis y desarrollarlo en una forma amena y cautivante, incluso para un lector no dedicado a la economía: a) su experiencia como novelista, con dos libros ya publicados, lo que le permite usar un

Daniel Artana (Buenos Aires, 1958). Licenciado en economía en la Universidad Nacional de La Plata. PhD en economía en la Universidad de California en Los Angeles. Economista jefe de la Fundación de Investigaciones Económicas Latinoamericanas (FIEL). Profesor titular de política económica en la Universidad Nacional de La Plata y profesor invitado de economía de la tributación en la Universidad Torcuato Di Tella. Email: daniel@fiel.org.ar 
lenguaje y una narrativa que atrapa al lector; b) su experiencia como economista profesional enfocado en los problemas del desarrollo económico, cualidad que lo ha convertido en uno de los más destacados en su profesión en las últimas décadas, carrera en la que ha publicado 14 libros y más de 200 artículos en revistas especializadas; y c) su conocimiento en persona de varios de los actores principales de la historia de Tanzania, ya que ha visitado el país en variadas ocasiones para realizar trabajos para organismos internacionales.

En una economía con una gran dependencia de ayuda externa hay una interacción permanente $-\mathrm{y}$ muchas veces una contradicciónentre los intereses de los funcionarios del gobierno y las agencias que aportan las donaciones o los organismos multilaterales que, además de contribuir con fondos, evalúan la sostenibilidad de las políticas económicas aplicadas. En Toxic Aid, Sebastián Edwards se preocupa por entender esa interacción y en qué medida puede haber influido en la toma de determinadas decisiones. El autor aplica a lo largo del libro el rigor de varias disciplinas de la teoría económica: la literatura de desarrollo económico (con el foco en las mejoras de productividad, la importancia de las instituciones, etcétera), la macroeconomía en economías abiertas (el problema de atraso cambiario, por ejemplo) y un análisis riguroso de las políticas sociales.

En un caso como éste, en el cual se observa un gran contraste en el desempeño económico a lo largo del tiempo, el enfoque aplicado por Edwards es un aporte importante para entender cómo y cuándo es más efectiva la ayuda internacional a países pobres, y qué puede explicar grandes éxitos y grandes fracasos en la toma de decisiones. Por ejemplo, ante la desesperante situación económica que vivía Tanzania a finales de los setenta, ¿qué puede explicar la profundización de políticas que ya habían demostrado su fracaso? ¿Por qué la insistencia en el error? En este ejemplo, como en otros a lo largo del libro, el enfoque de Edwards (mezcla de narrativa y de análisis económico riguroso) es central. Mi conclusión, luego de leer el libro, es que no hay una explicación única.

Las decisiones a veces obedecen a las tradiciones del país y a la visión de Julius Nyerere, quien fue su Presidente formalmente hasta 1985 pero que luego ejerció una influencia que se extendió hasta su fallecimiento, en 1999; a veces obedecen a una concepción errada de los analistas domésticos e internacionales sobre la eficacia de determinadas 
políticas de desarrollo (que a su vez fue cambiando notablemente en el tiempo); y a veces obedecen a una visión de la ayuda internacional excesivamente paternalista, que no tomaba en cuenta de manera adecuada las restricciones de la economía de Tanzania. Y es aquí donde aparece el aporte de Edwards al debate sobre "ayuda internacional sí o no". De mi lectura del libro, es claro que el autor demuestra que, dependiendo de cómo se la instrumente, la ayuda puede ser tóxica o ser efectiva para remover obstáculos al desarrollo y mejorar las condiciones de vida del país receptor.

Toxic Aid también permite ver que hay fenómenos que se repiten de un país a otro. En el momento de gran crisis de las decisiones populistas del gobierno de Tanzania surge casi "naturalmente" la búsqueda de "culpables" dentro y fuera del país, o se profundizan medidas erradas a la espera de una solución mágica que evite pagar costos políticos. La utilización de regulaciones y controles innecesarios que sólo generan grandes costos en el mediano plazo y, en el mejor de los casos, un pequeño beneficio de corto plazo fue un tema recurrente en las experiencias de los países latinoamericanos y africanos en las décadas de los setenta y ochenta, e incluso encuentra hoy algunos ejemplos aislados en nuestra región (por ejemplo, la Argentina y Venezuela).

En el capítulo dos del libro, Edwards resume la visión de los organismos multilaterales que consideran a Tanzania post 1996 como un éxito económico; sin embargo, destaca que uno no puede entender lo ocurrido desde ese año en adelante sin tener en cuenta el desempeño desastroso de los años previos, consecuencia, entre otros factores, de políticas erradas avaladas por los donantes. Además, hay problemas con la calidad de las estadísticas oficiales y muchas veces se pasa por alto la corrupción. Eso abre la puerta para el análisis detallado del resto del libro.

El capítulo tres es un excelente resumen de las diferentes visiones sobre desarrollo económico y ayuda internacional que han existido desde 1950 a la fecha. En el momento en que los países desarrollados le dan mayor peso a la ayuda — cosa que ocurre desde mediados de la década del 40-, en un extremo está la idea de que sólo es necesaria la ayuda humanitaria, en tanto que debe primar la economía de mercado; en el otro, se sostiene que la ayuda internacional a países pobres es indispensable para aumentar el stock de capital y desarrollar la industria 
sustitutiva de importaciones. Con el pasar del tiempo, estas posiciones diferentes van incluyendo nuevos desarrollos a partir de los trabajos de numerosos analistas, al punto de que hoy podemos decir que hay dos visiones opuestas respecto de la eficacia de la ayuda internacional.

Por un lado, un grupo, liderado por William Easterly, destaca el problema de incentivos "dobles" entre quienes son los que en verdad aportan los fondos (los contribuyentes de los países ricos), los que deberían recibir la ayuda (las familias pobres de los países receptores) y los agentes ejecutores, que persiguen sus propios intereses (las burocracias de las agencias de ayuda y del gobierno receptor). Esto produciría una suerte de cartel de agencias de ayuda, renuente a innovar y que "cobran caro por su servicio". La conclusión es que, en el mejor de los casos, mucha ayuda tiene escaso impacto.

Por otro lado, el grupo liderado por Jeffrey Sachs sostiene que la ayuda internacional puede ser efectiva, pero sólo si está focalizada en determinados programas (agua potable, infraestructura, agricultura, enfermedades contagiosas y educación). La clave es un análisis "clínico" que tenga en cuenta las características de cada país.

La importancia del trabajo de Edwards, que realiza un recorrido detallado a lo largo del tiempo en un mismo país, es evidente cuando se analizan los problemas de los estudios empíricos sobre ayuda internacional. Los estudios de corte transversal o paneles que incluyen varios países en diferentes momentos del tiempo no pueden más que aportar evidencia frágil. Ello ocurre porque al mirar datos agregados se pierde de vista que la ayuda actúa a través de varios canales y su efecto sobre el desarrollo depende de varios factores (la condicionalidad, cuál es el conocimiento del país en cuestión, la habilidad del gobierno de implementar las políticas, etcétera). Ése es, precisamente, el foco de Toxic Aid.

Al final del capítulo tres, Edwards incluye una síntesis de dos aportes importantes: a) el trabajo de Paul Collier de 2007, ${ }^{1}$ quien encuentra que la ayuda internacional ha aumentado el crecimiento de los países africanos pero tiene rendimientos decrecientes, para concluir que la condicionalidad en los programas de ayuda es un error, de allí la importancia de la ayuda técnica; y b) el trabajo de Abhijit Banerjee y Esther

${ }^{1}$ Paul Collier, The Bottom Billion: Why the Poorest Countries Are Failing and What Can Be Done About It (Oxford: Oxford University Press, 2007). 
Duflo de 2011, 2 quienes enfatizan que hay ejemplos exitosos y grandes fracasos y que se requiere la utilización de modelos de evaluación, por ejemplo, los llamados análisis de diff in diff, que comparan los resultados de un grupo que ha recibido un tratamiento (que sería en este caso la ayuda) con un grupo de control sin tratamiento.

En el capítulo cuatro, Edwards incluye información que demuestra la importancia de la ayuda recibida por Tanzania, tanto durante el período de fracaso como en el de éxito. También demuestra que la ayuda osciló en función de la relación del gobierno con los donantes y los organismos multilaterales. Apunta, además, que sí parece haberse observado un cambio entre ambos períodos: en el primero abundan los proyectos de inversión grandes, con varios ejemplos de "elefantes blancos", mientras que en el segundo la ayuda estuvo más orientada a programas sociales.

El capítulo cinco es importante porque Edwards narra los sucesos de noviembre de 1979, que terminaron con la expulsión de la misión del Fondo Monetario Internacional (FMI) del país, cuando Nyerere decidió que no iba a devaluar ni a reducir el déficit de las empresas públicas. Allí el autor se remonta a la Declaración de Arusha de $1967,{ }^{3}$ en la cual el Presidente Nyerere sienta las bases del socialismo africano que quiso para su país. En la visión del mandatario — que no era marxista, sino católico y admirador del socialismo fabiano-, el Estado debía ser dueño de los medios de producción (quizás ello explica su resistencia a reconocer el fracaso en la gestión de las empresas públicas) y los agricultores debían trabajar en granjas colectivas. En esta visión, las señales de precios eran poco relevantes y ello quizás explique el porqué de la negativa a mejorar el tipo de cambio real.

Lo curioso es que ese programa esbozado en 1967, y que va cobrando forma en varios planes quinquenales, fue apoyado por los donantes nórdicos e incluso recibió pocas críticas del Banco Mundial. La idea de forzar la colectivización de la producción agrícola, aun a pesar de la resistencia de los campesinos, se sumó a precios muy distantes de

${ }^{2}$ Abhijit Banerjee y Esther Duflo, Poor Economics: A Radical Rethinking of the Way to Fight Global Poverty (Baltimore: Johns Hopkins University Press, 2011).

${ }^{3}$ Documento presentado por Nyerere el 3 de febrero de 1967 al comité ejecutivo nacional del Tanganyika African National Union (TANU), entonces único partido de Tanzania, el que lo aprobó rápidamente. 
los internacionales para generar un colapso de la producción del sector. Las reservas internacionales cayeron a sólo 3,5 semanas de importaciones en 1978 (comparado con las 30 semanas una década antes), lo que aumentó la dependencia de la ayuda. La brecha cambiaria se disparó y la economía se contrajo.

El colapso económico es analizado con detalle en el capítulo seis. Edwards analiza por qué Nyerere no aceptó la sugerencia de devaluar la moneda para resolver la crisis externa. Quizás fue influido por alguno de sus ministros que descreían de los incentivos de precios o esperaban un efecto contractivo de la devaluación (a la Díaz-Alejandro). El hecho es que en 1980 los funcionarios del Gobierno se reunieron con otros representantes de países en desarrollo que criticaban al unísono las políticas del FMI y equivocadamente descreían de los incentivos de precios. No es el primer ejemplo ni el último de países que apoyan las decisiones equivocadas de un tercero, que termina siendo una especie de conejillo de Indias que paga los costos de las decisiones equivocadas.

El cambio de opinión entre los economistas respecto de la eficacia del Estado, así como la literatura citada por Edwards, que hubiera servido de soporte para adoptar políticas alternativas, lamentablemente llegaron algunos años más tarde de lo necesario para influir en un cambio radical en la política económica adoptada por Tanzania. El gobierno recibió algún apoyo de los organismos multilaterales en 1980, pero lo perdió al incumplir todas las condicionantes de los programas acordados. De todas maneras, Edwards destaca que Tanzania mantuvo la ayuda bilateral hasta mediados de los ochenta, cuando los países nórdicos reaccionaron ante la percepción de que se malgastaban los fondos. El propio Nyerere admitió en un reportaje concedido a la televisión Noruega en 1985 que las políticas no habían sido exitosas. Así empezó a gestarse la semilla del cambio: una pequeña liberalización de las restricciones del mercado cambiario, lo que coincidió con cierto avance de las ideas pro mercado en el mundo. Es interesante destacar que el problema del déficit de las empresas públicas, el atraso cambiario y las distorsiones de precios relativos también aparecieron en otros fracasos económicos de la región, como atestigua el caso de Zimbabwe muchos años después.

En el capítulo siete Edwards relata la decisión del Presidente Nyerere de no presentarse a nuevas elecciones. De todas maneras, retuvo el 
poder de facto. El nuevo mandatario firmó en 1986 un acuerdo con el FMI que comprometía pocos fondos (sólo el 60 por ciento de la cuota del país), lo que revela dos cosas: la desconfianza del organismo luego de siete años sin relación formal con Tanzania y que el FMI era el sello de calidad que permitiría desbloquear otros fondos, en especial de los donantes.

El programa requería una maxi devaluación (135 por ciento como la medimos en Latinoamérica), consistente con cambios en las políticas fiscal y monetaria y reformas estructurales que tenían por objetivo remover varios controles innecesarios, de modo de crear un marco adecuado para ganar eficiencia y productividad. La aprobación del programa fue un golpe importante para la vieja guardia del partido TANU, la que, a la larga, terminó ganando la batalla al diluir buena parte del esfuerzo de ajuste macroeconómico.

Pero entonces no había muchas alternativas al programa, porque el país había entrado en una etapa de destrucción. Edwards aporta varias razones que pueden explicar tanta demora en corregir desequilibrios tan obvios. Por un lado, las oportunidades de expresar disenso eran muy limitadas. Luego, los donantes nórdicos mantuvieron la ayuda hasta 1983-1984, ya que atribuían los problemas del país a los gastos que había generado la guerra con Uganda, la sequía de mediados de los setenta y al deterioro en los términos del intercambio. Además, todavía no era evidente el fracaso de las ideas de planificación centralizada y controles por doquier. Pero la razón más importante, para Edwards, es la economía política del proceso de reformas. Los funcionarios públicos y los obreros que trabajaban en las ciudades disfrutaban de la renta capturada a los agricultores gracias a la fijación de precios menores a los internacionales. Junto con eso, se generó el típico caso de ganadores de las reformas dispersos y perdedores concentrados con gran capacidad de lobby. Aunque varios años de crisis profunda fueron licuando el poder de los grupos que obtenían favores del Estado, ellos continuaron resistiendo, otorgando más prebendas y apelando al nacionalismo anti-FMI y a las teorías conspirativas (rasgo típico en algunos países de Latinoamérica incluso en la actualidad). Pero la duración de la crisis fue produciendo un apoyo creciente a aceptar un programa con el FMI. En otros países, en esas circunstancias se abre el juego a los tecnócratas. Sebastián Edwards destaca aquí una particularidad de Tanzania: la es- 
casez de tecnócratas, al menos influyentes o con posibilidades de tener puestos claves para realizar las reformas. Es interesante la mención al seminario organizado por una universidad local en 1984, en el cual se discuten varios trabajos y aparece un consenso acerca de la necesidad de cambiar el rumbo. Pese a esto, los académicos que participaron no formaron parte del gabinete de ministros.

A fines del año 1986 y como resultado de la firma del acuerdo con el FMI, las "ruedas de la ayuda internacional" empezaron a girar de nuevo, pero con condicionantes atadas al cumplimiento de las metas del programa firmado con el Fondo. Además, y a diferencia de lo ocurrido en las décadas anteriores, la ayuda no financió grandes proyectos de inversión, sino variados programas, algunos poco habituales, como proveer fondos para importaciones. La economía de Tanzania estaba destruida y se necesitaba reconstruirla. Sirva como ejemplo que la producción industrial había caído en 70 por ciento entre 1979 y 1984. Esta tarea es la que revisa Edwards en el capítulo ocho de su libro.

La descripción que realiza el autor de la difícil reconstrucción me hizo recordar la monumental tarea de las economías detrás del muro de Berlín: lograr un mínimo de confianza y que empezaran a funcionar los mercados era un serio desafío.

La reconstrucción fue ambiciosa, con reformas en varios frentes. A pesar de que estaban poniéndose de moda las propuestas que en 1989 dieron lugar al llamado Consenso de Washington, el enfoque adoptado en Tanzania fue muy pragmático, lo que no evitó, sin embargo, que fuera resistido por la vieja guardia que había disfrutado de los privilegios del sistema anterior. El propio ex Presidente Nyerere se encargó, a través de su influencia como líder del partido oficial, de enlentecer el cambio. Los gerentes de las empresas públicas obviamente lo apoyaron con entusiasmo e hicieron todo lo posible para no perder sus privilegios (entre otros, protección desmedida y subsidios del Tesoro).

La depreciación de la moneda fue acompañada de una flexibilización que le dio aire a la economía: la posibilidad de importar con dólares propios o de exportación le permitió al sector privado acceder mínimamente a insumos básicos para la producción, así como a algunos equipos importados. Pero el escaso avance en otras medidas de "liberalización" impidieron una recuperación en la producción agrícola, y el FMI empezó a perder la paciencia con el gobierno. Esta tensión explotó 
cuando en 1988 las autoridades decidieron frenar el deslizamiento cambiario gradual - también conocido como "crawling peg"-, lo que produjo una nueva apreciación de la moneda medida en pesos constantes.

Pero la renuncia de Nyerere al partido oficial en 1990 movilizó nuevas reformas apoyadas por el Banco Mundial. Muy importante fue la autorización de algunas operaciones en un mercado cambiario libre que, al extenderse, permitió virtualmente eliminar la brecha cambiaria para el año 1993. No obstante, las demoras en avanzar en otras medidas que promovieran aumentos en la productividad (por ejemplo, reformas pro competencia o privatizaciones) impidieron un mejora más rápida de la economía. A pesar de la presión de los organismos multilaterales, se frustraron casi siempre las propuestas orientadas a dar al sector privado un mayor papel en la economía.

Los donantes nórdicos pusieron el énfasis en revertir la seria declinación que se observaba en la educación. Desde comienzos de los noventa, y por presión del Banco Mundial, se trató de cobrar un cargo por acceder al nivel medio y las universidades, pero luego de protestas estudiantiles el gobierno abandonó la idea. Sí se logró alguna flexibilidad en 1995, al permitirse las escuelas privadas. En el campo de la salud hubo mucha superposición y falta de coordinación entre los variados programas apoyados por los donantes.

Dado el mísero punto de partida, la economía mostró un fuerte crecimiento en la segunda mitad de la década de los ochenta, pero luego se paralizó nuevamente durante el primer quinquenio de la década siguiente. Aumentó la inversión, pero la medición de productividad total de los factores - negativa - sugiere que se concretaron muchos proyectos malos. El mal desempeño de la economía y las sospechas de corrupción llevaron a los donantes nórdicos a reducir la ayuda.

Aquí, Edwards destaca un punto central para explicar el desempeño mediocre de la economía: la falta de apoyo de los funcionarios públicos de alto rango, quienes atribuían los problemas a la sequía, al deterioro de los términos del intercambio o a las consecuencias de la guerra con Uganda. El acercamiento al FMI era una movida desesperada ante la falta de divisas. Pero la falta de apoyo del establishment local se mostró como una diferencia importante, comparado con los casos de Chile o Colombia, que tuvieron reformas importantes más o menos en esa misma época. 
El servicio de la deuda externa comenzó a trepar nuevamente y alcanzó el 60 por ciento de las exportaciones en 1991. Los funcionarios de Tanzania comenzaron a solicitar una condonación de una parte de lo adeudado (lo que finalmente se logró una década más tarde dentro de la iniciativa Debt Relief Under the Heavily Indebted Poor Countries (HIPC), llevada adelante por el FMI y el Banco Mundial a partir de 1996).

Las idas y vueltas entre el gobierno y la comunidad internacional de donantes permitieron algunas adaptaciones del liderazgo local posiblemente con el fin de ganar algún espacio. Por ejemplo, luego de la caída del muro de Berlín, el todavía líder del partido único, Nyerere, propuso una reforma constitucional para abrir el juego a otros partidos. Esta reforma se aprobó en 1992.

En el capítulo nueve, Sebastián Edwards analiza el gran cambio que aparece cuando el gobierno empezó a hacer suyos los programas de ayuda. En 1994, un gran escándalo de corrupción fue descubierto y puso en evidencia un faltante importante de ingresos públicos. La consecuencia sobre el flujo de ayuda fue inmediata. Entre 1994 y 1995, los donantes redujeron el apoyo en forma coordinada y se decidió crear un grupo independiente que evaluara los programas de ayuda. Curiosamente, este grupo tenía (y de hecho lo hizo) que mediar entre el gobierno y la comunidad de donantes. El informe Helleiner se distribuyó a mediados de 1995, confirmó los problemas y sugirió un mayor involucramiento del gobierno local en la elección y diseño de los programas a financiar. La palabra final debía tenerla el gobierno. La idea de la "propiedad" de los programas en manos de la administración central fue clave en el éxito posterior (e incluso generó externalidades positivas en el diseño de programas de ayuda en otros países pobres).

La pérdida de popularidad del gobierno motivó el apoyo creciente a un candidato que, a priori, tenía pocas chances pero que contaba con un activo valiosísimo: su gran honestidad. Finalmente, Benjamín Mkapa fue elegido Presidente a finales de 1995. Su estrategia fue acercarse a la comunidad internacional para lograr un alivio respecto de la deuda externa. Además, el nuevo Presidente comprendía que el mundo se había movido hacia economías más orientadas por el mercado y que una economía pequeña como Tanzania no podía seguir remando contra la corriente. 
Con avances concretos hacia una mayor transparencia, más la convicción de cambiar, el gobierno de Tanzania logró un nuevo apoyo del FMI y de la comunidad internacional. Para lograr vencer la resistencia interna, Mkapa implementó un sistema de premios (participar en las nuevas actividades abiertas al sector privado) y castigos (despidos e investigaciones por corrupción). Se inició así el camino hacia el "éxito" económico.

En el capítulo diez, Sebastián Edwards menciona que el Presidente Mkapa tenía una visión diferente sobre la Declaración de Arusha y su objetivo de mover la sociedad hacia el colectivismo, idea que había gobernado Tanzania durante años. Esto queda plasmado en el documento oficial de 1997 que, en el tercer año del primer mandato presidencial de Mkapa, presenta un programa de desarrollo al 2025 que mantiene los objetivos sociales de la Declaración de Arusha, pero toma distancia de su filosofía económica. Se enfatiza la importancia de los mercados, la competencia, las instituciones, la transparencia y el estado de derecho, revelando la influencia del Banco Mundial en el contenido del programa.

Las reformas de la década 1986-1995 habían puesto el foco en temas macroeconómicos con un énfasis particular en reducir la brecha cambiaria y aliviar la restricción de divisas. En el período post $1996 \mathrm{se}$ incluye una serie de reformas micro, que procuran aumentar la eficiencia y la productividad, incrementar la inversión y achicar el Estado. El Presidente empujaba las reformas y trataba de ganar espacio respecto de la vieja guardia, mediante medidas que apuntaban a reducir la corrupción que la mayoría de la sociedad percibía como un problema importante. Sin embargo, los avances hacia la transparencia reclamados por la comunidad de donantes se frustraron. Aquellos que reemplazaban a los funcionarios sospechosos de corrupción pronto aparecían envueltos en nuevos escándalos.

Las reformas orientadas a mejorar las cuentas públicas eran necesarias para que el gobierno de Tanzania pudiera aportar fondos propios al desarrollo de los programas, aportes conocidos como fondos de contraparte, requeridos por los donantes como complemento a las divisas que entregaban ellos. A comienzos de 1997, el Club de París concedió una reducción en la deuda de mil millones de dólares, que fue seguida por importantes aportes de agencias de desarrollo de los países desa- 
rrollados y, algunos años después, por un alivio dentro de la iniciativa HIPC.

La descripción que hace Edwards de las medidas adoptadas por el gobierno de Mkapa muestra varios puntos de contacto con la experiencia de otros países en desarrollo con dificultades económicas: se reemplaza un anticuado impuesto a las ventas por un IVA, se reducen exenciones tributarias, se privatizan (al principio tímidamente) algunas partes de la provisión de energía, se trata de mejorar el servicio civil y achicar una planta de empleados estatales sobredimensionada luego de años de decisiones populistas, se controlan los excesos (por ejemplo, pagos a empleados fantasma), se reforma la legislación para permitir inversionistas extranjeros en recursos naturales (minería en el caso de Tanzania) y, en una novedad para el país, se flexibiliza el acceso a la tierra agrícola, incluso a las mujeres.

Durante la segunda presidencia de Mkapa, que empezó a finales del año 2000, el proceso de privatizaciones cobró mayor relevancia. En sólo dos años se transfirieron a manos privadas 326 de las 390 empresas públicas contenidas en la lista de entidades a privatizar (incluso algunas se vendieron a inversores extranjeros).

Durante la gestión de Mkapa, Tanzania promedió un crecimiento de casi 6 por ciento anual, mejoró la solvencia fiscal y se expandieron las exportaciones. Las principales críticas se centraron en la educación y en la poca mejora en las instituciones, especialmente debido a los escasos avances en transparencia y en reducir la corrupción.

El Presidente Mkapa influyó decisivamente en la elección del candidato oficial para las votaciones presidenciales. Apoyó a quien fuera su rival en la interna del partido oficial en 1995, Jakaya Kikwete, quien se había desempeñado como ministro de Relaciones Exteriores y, por ende, aparecía alejado de sospechas de corrupción. Kikwete asumió como Presidente a finales de 2005, trayendo consigo los tres ejes de su campaña: el sector agrícola, la lucha contra la corrupción y la seguridad ciudadana. Estas prioridades se destacaron en los programas de desarrollo de su administración, que profundizaron el sesgo pro mercado de la gestión del Presidente Mkapa. La mejora de la economía de Tanzania se reflejó también en los indicadores del "Doing Business" que publica el Banco Mundial: en 2012 el país aparece en el primer tercio de los países de África Subsahariana (y en el puesto 134 de las 185 naciones del mundo incluidas en el estudio de ese organismo). 
En los quince años posteriores a 1995, la economía de Tanzania tuvo una mejora importante. El alto y sostenido crecimiento económico fue acompañado de: a) un aumento en la inversión de 17 por ciento del PIB en 1999-2002 a 30 por ciento del PIB en 2010-11; b) una reducción a la mitad de la deuda externa a 30 por ciento del PIB y una mejora en la posición de reservas internacionales; c) una inflación de un dígito anual en la mayor parte del período y estabilidad cambiaria; d) un salto en las exportaciones de 15 por ciento del PIB a finales de los noventa a 30 por ciento del PIB; y e) mejoras en los indicadores sociales básicos (un aumento de ocho años en la expectativa de vida, matrícula primaria superior al cien por ciento de los niños en edad escolar y un fuerte aumento en la matrícula secundaria).

El aumento en la tasa de crecimiento se explica en buena medida por un alza en la productividad total de los factores, que, de mostrar registros negativos, pasa a incrementos del orden de 2 a 3 por ciento anual luego de 1996.

Una medida más amplia del progreso, como el Indicador de Desarrollo Humano (IDH) que elabora las Naciones Unidas, también refleja el progreso de Tanzania. En 1990, el IDH de Tanzania era 10 por ciento inferior al de África Subsahariana y en 2012 lo superó levemente. Sin embargo, Edwards destaca algo que elabora en los capítulos finales de su libro: la impresionante mejora económica no llevó a una reducción importante en la pobreza — sólo se redujo en tres puntos porcentuales en casi tres décadas-, como sí ocurrió en otras experiencias exitosas.

El éxito económico también se nota en los temas de debate. En el pasado, la brecha cambiaria, la falta de divisas, la recesión, el desempleo y la migración interna del campo a la ciudad eran los problemas más debatidos. Más recientemente, el foco de discusión se centra en dos problemas: la corrupción y la relación tirante entre el gobierno local de la isla de Zanzibar (muchas veces administrado por un partido local) y el gobierno central de Tanzania (siempre en manos del partido oficial).

Sebastián Edwards menciona que, sorprendentemente, los donantes y los organismos multilaterales le dan menos peso del debido al problema de la corrupción.

En el último capítulo del libro el autor hace un análisis profundo (y a la vez provocativo) para responder a la pregunta: ¿Es Tanzania una historia exitosa? 
La historia relatada por la comunidad internacional puede resumirse en un ejemplo del éxito de políticas de mercado y de la eficacia de la ayuda internacional desde 1996 en adelante. Muchos datos macroeconómicos avalan esta conclusión. Sin embargo, una visión más larga, como la que adopta Edwards en su libro, muestra que la ayuda fue tóxica en las décadas previas a 1996 y no pudo evitar (quizás contribuyó a) la virtual desintegración de la economía del país.

El autor discute, además, dos temas cruciales para completar el análisis del caso de Tanzania: la calidad de los datos oficiales y el impacto de las reformas sobre la calidad de vida de la población. Y finalmente cierra con un análisis contrafáctico de qué hubiera pasado si en lugar de adoptar medidas intervencionistas extremas el país hubiera adoptado políticas más sensatas antes de 1996.

La calidad de los datos oficiales es mala. En parte, ello se debe a la dificultad de medir apropiadamente al sector de subsistencia informal, que tiene una participación importante. Las revisiones del PIB que se hicieron en Tanzania para medir mejor la economía informal no permiten encadenar las series hacia atrás. Las serias distorsiones de precios relativos complican incluso la medición del nuevo año base y producen subestimaciones serias. Un ejemplo obvio son las exportaciones registradas en momentos de alta brecha cambiaria, que son menores a las verdaderas (que incluyen las subfacturadas para poder ser contrabandeadas a dólares libres). Otro ejemplo es la inversión, que en el caso de bienes de capital importados también sufre de una exageración para poder acceder a más dólares al precio oficial.

Estos problemas aparecen en otros casos de países en desarrollo con alta informalidad y serias distorsiones cambiarias y de precios relativos. Pero el caso de Tanzania va más allá. Edwards relata que el PIB del sector agrícola parece ser "inmune" a los cambios climáticos. Por ejemplo, en 2005 el PIB agrícola prácticamente no cae a pesar de que el país sufrió la peor sequía en veinte años.

Los datos de la Encuesta de Gasto de los hogares tampoco reflejan el mayor crecimiento que en principio debió reflejarse en mayor consumo (aunque una explicación parcial podría ser que la gente aumentó el gasto en bienes durables, lo que no se registra adecuadamente en las encuestas de gasto). Tampoco la pobreza se redujo en la medida en que hubiera sido esperable en una economía creciendo al 6 por ciento anual. 
La paradoja de alto crecimiento y poca reducción en la pobreza (incluso comparado con otros países africanos) confirma el escepticismo sobre las estadísticas oficiales.

Los ejercicios contrafactuales presentados por Edwards permiten ver que más que una historia muy exitosa post 1996, Tanzania es un ejemplo de una gran recuperación luego de un gran desastre. De todas maneras, la pérdida acumulada por los errores anteriores a 1996 es monumental y, en definitiva, la capacidad de la sociedad de cambiar su curso no debe ser subestimada.

La última sección es la que le da el nombre al libro. Aquí Edwards resume el análisis de capítulos anteriores con ejemplos de ayudas internacionales que apoyan programas muy malos (como la obligación impuesta a los agricultores de trabajar en granjas colectivas) o que ignoran distorsiones serias de precios relativos en contra del sector más importante de la economía. Edwards rescata al FMI como el organismo que mantuvo una visión coherente a lo largo del tiempo sin dogmatismos y aceptando cierta heterodoxia.

La conclusión de Edwards es que la ayuda internacional durante las dos primeras décadas post independencia fue tóxica y corresponsable de uno de los mayores fracasos económicos vividos por una nación pobre. Los cambios posteriores son consecuencia de múltiples factores: los problemas crónicos en Tanzania, el cambio de visión en los países desarrollados respecto de la política económica y nueva evidencia acerca de qué ayuda es más efectiva. También es cierto que la presión de los donantes desde 1985 impulsó los cambios políticos que hicieron posible que el país modificara el curso e iniciara un proceso de recuperación diez años más tarde.

Y la nueva forma de ayuda, con mayor participación del gobierno de Tanzania y mayor preponderancia de programas más pequeños, fue crucial para el cambio. En resumen, Edwards califica a la ayuda internacional a Tanzania con un desaprobado contundente entre 1961 y 1981, con un aprobado entre 1981 y 1994 y con una buena nota (pero no sobresaliente) luego de 1995.

En resumen, el libro de Edwards nos muestra que la eficacia de los programas de ayuda no puede medirse con regresiones de corte transversal. Es necesario analizar el caso de cada país con detalle, tratando de entender que existen muchas cajas negras que necesitan ser abiertas 
y analizadas en detalle para poder concluir respecto de qué funciona y qué no. En mi opinión, esto hace más difícil replicar las historias exitosas. La economía política de las reformas varía de un país a otro y la interacción con la comunidad de donantes, también. Ello destaca todavía más la importancia de contar con una burocracia calificada, que pueda aportar al diseño y ejecución de los programas con adecuados controles que reduzcan las oportunidades para la corrupción y la ineficiencia. EP 